\title{
On Improvement of Academic Abilities of Undergraduates in Local Colleges
}

\author{
Chunyan $\mathrm{Yan}^{\mathrm{a}, *}$ and Wentao $\mathrm{Yi}^{\mathrm{b}, *}$ \\ College of Chemistry, Chemical Engineering and Material Science, Zaozhuang University, \\ Zaozhuang 277160, China. \\ aqislycy@163.com, ${ }^{b}$ qislywt@163.com \\ * The Corresponding Author
}

Keywords: Academic abilities; Innovation; Solutions; Applied talents

\begin{abstract}
College students' academic ability is of great importance for their future development, and it is the requirements for the quality education and social development. It is also vital for the colleges and universities to cultivate the spirit of innovation and practical abilities of the students, which are connected tightly with the students' academic abilities. The general situation of contemporary local college undergraduates in the cultivation of their academic literacy and innovation ability is analyzed in this paper.The reasons for the poor innovation initiative and the low academic ability of the undergraduates are discussed. And suggestions such as the organization of extracurricular academic activities to establish academic awareness and ability of the undergraduates are proposed through four aspects.
\end{abstract}

\section{Introduction}

In 21th century, knowledge-based era, countries all over the world are competing to cultivate high-quality innovative talents as an important strategy for national development. Colleges and universities shoulder the important responsibility of cultivating creative talents for the country. In response to the national call, some provincial colleges and universities have turned to application-oriented local universities, and the cultivation of students has also changed to application-oriented. Among them, practical teaching of professional talents is an important way to cultivate students' practical ability and applied innovation ability. Each school provides some practical opportunities such as curriculum design, internship practice stage, graduation design and social investigation to improve students' ability of application and innovation. However, it is found that students do not know how to search the documents when doing a dissertation or an open experiment which requires students to find the literatures. Even when they encountered problems in the experiment, they do not know how to find the solution to the problem and so on.

In recent years, it is a good way to cultivate creative talents with innovative consciousness and innovative abilities by carrying out the extracurricular academic and technological competitions for college students. The students' academic awareness and ability to innovate, to some extent, represents the level of academic innovation capability of the university [1]. Through the development of "Challenge Cup", Innovation Entrepreneurship Competition, National Innovation Entrepreneurship Program and graduation thesis, it is found that students are highly dependent on the guidance of teachers. Basically, the students just followed the guidance teacher's plan, and most of the research ideas were taken from the instructor. The poor innovation initiative and the low academic literacy led to the difficulty to obtain a better ranking in some high-level competitions. Due to the smattering knowledge, they can't convince others with their own opinion.

The reasons for these problems are as follows: (a), students are inert in learning new knowledge. Their self-study ability is relatively poor, and they are not good at finding information about related problems in learning, academic trends and research methods from the internet [2]. (b), Due to the strong sense of utility, some students did not put how to improve their own academic research capabilities, professional quality in the first place. Everyone has the potential to innovate or create. The driving force for academic exploration is how to stimulate it. Academic consciousness is the foundation of innovation ability. Therefore, it is particularly important and urgent to strengthen the 
training of academic ability, to focus on guiding students to improve their independent learning desire, to stimulate their desire for innovation with academic research, and to enhance students' consciousness of exploring scientific and technological innovation.

The improvement of academic literacy ability can be realized by learning, finding, exploration and practice three steps. Learning refers to the acquisition of new knowledge, which is the most basic ability to train. By learning some basic retrieval knowledge and skills, students will realize where to check and how to search literatures when they encounter unknown problems. Discovery is to promote students to think with questions. Exploration and practice is the beginning of innovation through careful observation and reflection. The teacher's main job is to guide and help students to achieve their own ideas and plans or give work objectives. Students must understand that their job is to be done by themselves and the teacher's job is only to assist with guidance. Specific suggestions to improve academic abilities of the undergraduates are proposed based on the exploration and practice at Zaozhuang University as follows.

\section{Open "Information Retrieval and Scientific Papers Writing" and other Information Literacy Education Curriculum to Establish Academic Awareness}

In the era of science and technology changing with each passing day, it is impossible for a man to make breakthrough achievements if he only has book knowledge without the ability to learn new knowledge by modern means other than books. Theoretical and practical understanding on the knowledge conversion to abilities showed that information provides help for academic achievements [3]. Therefore, it is very necessary to set up such a course or lecture to teach some search skills and practical experience. In order to improve the teaching quality of this course, students of the same discipline or major should be collected and have the same class as much as possible. The contents of lectures should be based on the students' specific majors and disciplines, focused on the retrieval of basic documents and thematic materials related to their disciplines, majors, highlighting professional features. The teachers should instruct the students to master the methods and skills for obtaining documents, and introduce the distribution of books and documents so that they can make rational use of the documents, enhance their ability to obtain information, reduce blindness and improve the efficiency of data retrieving. Targeted teaching will enable students to understand the discipline or professional research frontier and development trends in-depth, and make students have interest in learning.

In order to improve the practical ability of students, some hot topics of academic research in recent years can be divided into several topics. With the topic as the carrier and the task of reporting as the driving force, the free knot students group can analyze and summarize the selected topics by consulting the literature. Finally, a summary of the text is formed and a 5-10 minutes small report is given. This way not only develops students' ability for document retrieval, analysis and summarization and language expression, but also mobilizes the initiative of students' autonomous learning and trains their self-learning ability largely. At the same time, a team spirit of the students is formed by the group members' discussion, communication, and cooperation with each other [4].

Through the combination of learning and research, self-learning can also promote students to accumulate new knowledge, to master new trends, to know the latest research progress in the field, and then they can put forward new ideas and find their own interest in scientific research. On the other hand, students can have a preliminary understanding of scientific research and lay a foundation for subsequent practical research.

\section{Provide Various Academic Lecture Environments to Guide the Academic Standardization}

Lectures and academic reports can reflect the spirit and campus culture of a university, which is the main way for students to acquire extensive knowledge and improve their academic attainment.

By attending the lectures on academic frontiers, the students can understand the research status of a certain academic field, update their knowledge, expand their view horizon, and inspire their curiosity to explore the unknown knowledge. By listening to the lectures on research experience and 
results of the expert, the students can learn the research designs, thinking methods and scientific research experiences from the experts, and open up new ideas for research and stimulate enthusiasm for scientific research with great concentration. However, the current situation is that the academic atmosphere of the local universities is not strong and the number of experts invited to give academic lectures is fewer, the students are often "asked" to attend the lectures without enormous interest. Thus, the expected effects of the lectures are reduced. In fact, listening to such kind of academic lectures often requires a certain amount of professional knowledge. If it is a non-professional lecture, the speaker is undoubtedly casting pearls before swine, and it is difficult for the students to understand the research results of the experts. The students should be encouraged to participate in various academic lectures, even if they don't understand the lecture contents. It is of great importance for them never to lose their confidence. If students know the lecture content or the research direction of the experts in advance, and with questions to attend the lecture, it will be useful to improve the effect of lectures [5]. It would be better to add interactive links and active atmosphere to enhance students' participation during the course of the lecture.

At the same time, the quality of lectures should be emphasized on the activities of academic lectures carried out by the local colleges. It is better to ensure that the theme of each communication activity is consistent with the needs of the students. Such lectures should be science popularized, having detailed and scientific contents. Thus, the students can learn the knowledge indeed. In addition, the academic lectures can be undertaken in the form of a series with a definite theme, impelling the student to "read and understand" thoroughly on an issue, and gradually emphasizing and deepening on the theme, laying a solid academic foundation for the future.

\section{Carry out Extracurricular Academic Activities Vigorously for College Students to Improve their Academic And Innovative Abilities in Practice}

The extracurricular academic science and technology activities of the college students refers to the popularization of scientific knowledge, academic research, inventions, science and technology production, science and technology development, science and technology services and other forms of activities conducted by the college students under the guidance and support of the colleges and teachers. This kind of activity is an effective way to cultivate students' scientific spirit, enhance students' overall competitiveness, and cultivate innovative talents who should meet the requirements of social development.

Extracurricular academic science and technology activities can be carried out relying on the open experiment courses, course contests before the training, student innovation fund project, participating in teachers' scientific research projects, national competition and other forms. This kind of activity can be organized in the form of "free group" and team cooperation so as to play the main body role of the students fully in extracurricular academic science and technology activities [6]. Teachers should adhere to the principle of heuristic induction that the students are not to be replaced or to be left alone. Besides, it is better to increase publicity and create a good atmosphere to attract more students to the academic science and technology activities, such as organizing scientific and technology culture festival, paper report meeting, competition of science and technology works, exhibition so as to improve students' practical abilities in various activities. "Challenge cup" national college students extracurricular academic science and technology works competition is a national competition with guidance, demonstration and mass features, which provides a great exercise opportunity for the college students [7]. The topics can be selected in the form of "teachers bidding" and "students self-declaration", so that the students can combine both the teachers' scientific research direction and their own interests and hobbies for the topic. At the same time, the research significance and feasibility of the topics should be demonstrated to further improve the quality of the selected topics, in order to form features and enhance the competitiveness. "Three rural areas" social practice is another good activity to fully improve the ability of the college students to serve the society. It is not only a form for the students to contact society, understand the society, but also an opportunity to go deep into the society and serve the society using the scientific knowledge to solve practical problems, achieving the purpose of "be educated, gain ability and do contributions". 
In the process of teaching, the reform of practical teaching should be strengthened. And the practical teaching and the practical activities of college students should also be put in a very important position to create an atmosphere and environment conducive to cultivate students' innovative ability. Conducting creative teaching activities such as discussion-based teaching, problem teaching and case teaching will create a democratic and relaxed atmosphere for innovation, and stimulate students' independent thinking [8]. It is necessary to let students feel and understand the process of knowledge generation and development. Great importance should be attached to cultivate students' scientific spirit and innovative thinking, to train the students' ability to collect and process information and acquire new knowledge. Their language expression and unity cooperation ability and ability to analyze and solve problems will be developed by social academic activities.

\section{Attract Social Forces, Especially Enterprises to Engage in Extracurricular Academic Scientific and Technology Innovation Activities}

Extracurricular academic science and technology innovation activities of the college students need adequate financial support on the one hand, and the achievements of science and technology innovation activities should be transferred to the production and application as soon as possible so as to promote the in-depth development of college students' academic scientific and technology innovation activities on the other hand. So, this requires the colleges or local universities to perfect the relevant regulations, formulate preferential policies to attract the participation of social forces, especially enterprise, so as to construct new scientific research and industrialization mode, establish incubation platform for the achievements, attract kinds of resources to participate in, create environment and platform for combination and jiont development of social capital and science and technology knowledge of the college teachers and students.

\section{Conclusion}

The ability of academic accomplishment cultivation is a long-term process, which requires long-term accumulation of students, requires schools, teachers and students to work together to give full play to students' learning initiative, requires exercise on the ability of students to observe, analyze and solve problems, which helps them to establish independent thinking, bold innovation, exploration of unknown academic awareness. Students' extracurricular academic activities of science and technology should be promoted to cultivate their innovative spirit, and to serve students' growth and development.

\section{References}

[1] N.Ali, K.Jusoff, S. Ali, N. Mokhtar and A.S.A. Salamat, Management Science and Engineering, 3 (2009) 81-90

[2] W.H. Yuan, R.R.Xu, Journal of Wuhan University of Science \& Engineering, 21 (2008) 58-60.

[3] M.N. Masrek and N.Z.M. Zainol, Procedia - Social and Behavioral Sciences, 174 (2015) 3603-3610

[4] J.L. Kruger, E. Hefer and G. Matthew, Journal of Eye Movement Research, 7 (2014) 1-15.

[5] X.Liu, Science Education Article Collects, 240 (2013) 147-148.

[6] Q. L. Feng, Journal of Higher Educatio n, 30 (2009) 96-99.

[7] Y. Yan, J.G.Yi, Pioneering With Science \& Technology Monthly, 21(2016) 41-45.

[8] G. Stephanou and A. Kyridis, International Education Studies, 5 (2012) 58-79. 